\title{
Research of Teaching Reformation Based on PBL and Resources Sharing in Digital Signal Processing
}

\author{
Xia WANG* \\ School of Electronic and Information Engineering \\ Hebei University of Technology \\ No. 5340, Xiping Road, Tianjin, 300401, China \\ wangyuehui3@163.com \\ Cuixiang LIU \\ School of Electronic and Information Engineering \\ Hebei University of Technology \\ No. 5340, Xiping Road, Tianjin, 300401, China \\ liucuix@126.com
}

\author{
Baozhu WANG \\ School of Electronic and Information Engineering \\ Hebei University of Technology \\ No. 5340, Xiping Road, Tianjin, 300401, China \\ wbz_china@126.com \\ Cheng ZENG \\ School of Electronic and Information Engineering \\ Hebei University of Technology \\ No. 5340, Xiping Road, Tianjin, 300401, China \\ zeng_ch@126.com
}

\begin{abstract}
Aim at reducing the contradiction between teaching time limitation and course contents in Digital Signal Processing course, this paper researched new teaching method based on resources sharing network platform, Problem-Based Learning(PBL) teaching mode and its application, and adopted several methods in routine teaching, such as main point based teaching, case-based teaching, etc. Resources sharing network platform provided curriculum resources and supplementary teaching resources, including syllabus, electronic course ware, studying guide, videos, and so on. PBL based teaching process included four stages, dividing students into several teams, searching information and references, exploring for solutions outside classroom by students, presentation and discussion in class. All of these reformation make teaching procedures more consummate, promote students' ability of signal analyzing and system design, and have important significance in improving teaching effect, promoting the development of teaching team, and training high quality talents.
\end{abstract}

Keywords-Digital Signal Processing, Autonomous Learning, Teaching Method Reformation, PBL, Resources Sharing

\section{INTRODUCTION}

With the rapid progress and development of digitization, digital signal processing technique plays an increasingly important role in signal processing areas. So "Digital Signal Processing" is an important basic disciplinary course of Electronic and Information Engineering major, Communication Engineering major, and serves as a connecting link between proceeding and following courses.

Higher Education Law of the People's Republic of China presents that the task of higher education is to bring up advanced specialized talents with innovative spirits and practice ability[1]. And the National Outline for Medium-and Long-Term Educational Reform and Development (2010-2020) also emphasizes training talents with high-quality and innovation[2]. So it's important to improve quality and effect of the course in undergraduate teaching, and cultivate the ability of autonomous learning, solving questions independently and creative thinking.

Many universities of science and engineering set up "Digital Signal Processing” course, carry a lot of research and reformation on content setting, teaching method and teaching means, and achieve many success, such as heuristic method, interactive teaching, etc[3-4]. There are also some research in practice teaching[5-6]. But there are still some problems to be resolved, for example, how to improve the ability of selfregulated learning, how to assure content integrity while class hours are reduced. All of these need us to change our teaching concept, introduce new teaching model to realize innovation of teaching method, and utilize modern information technology to share education resources. Problem-Based Learning(PBL) is a hot topic concerned by educators in recent years, and many studies focus on teaching and practice based on PBL[7-9]. This paper discusses teaching reformation process in Digital Signal Processing Course of our school, i.e. PBL application and resources sharing network platform construction.

\section{RESOURCES SHARING NETWORK PlATFORM CONSTRUCTION}

Resources sharing which base on network reflect synergism between students and teachers, and contribute to explore new ideas of reformation and development of higher education with Chinese characteristics[10]. To fasten the construction of resource sharing course has a very important significance in deepening teaching reformation and improving teaching quality. Constructing network platform is the basis of resources sharing course.

Digital Signal Processing course is an important link of Signal and Linear System and its Curriculum Design, and it is also a necessary tache in learning signal theory and its application for students. Construction of resources sharing network platform can assure integration of teaching contents and knowledge hierarchy, and achieves teaching goals. Currently, we have established Digital Signal Processing Course Platform relying on course center of Hebei University 
of Technology; Framework of Resources Sharing Platform is shown in Fig.1. From the website, students can download curriculum resources, such as course introduction, syllabus, electronic course ware, etc., and get supplementary teaching resources, such as studying guide, videos of experimental demonstration, and so on. This platform helps students selflearning, and improves learning efficiency and effect.

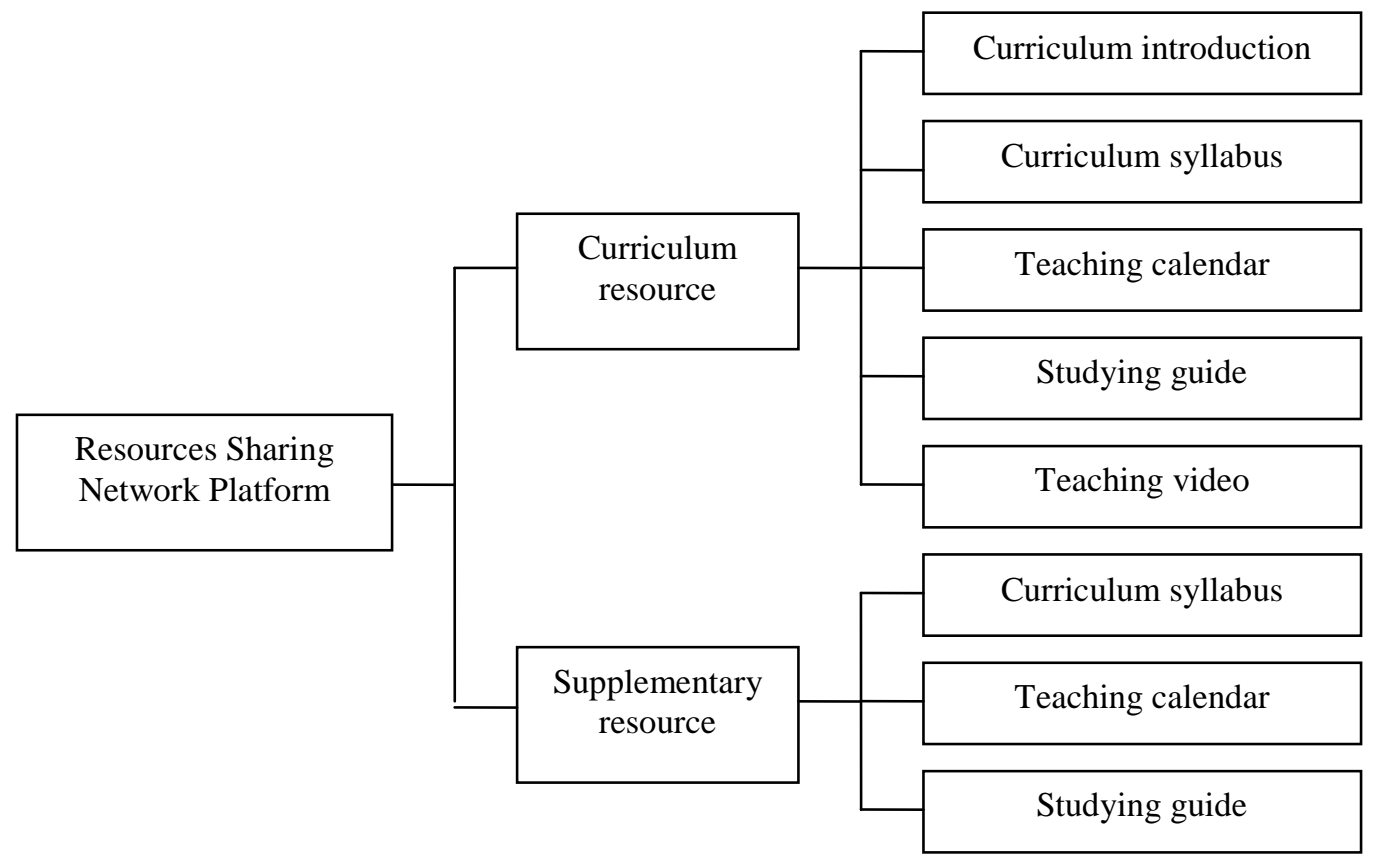

Fig. 1.Framework of Resources Sharing Platform

\section{PROBleM-BASED LEARNING}

Problem-Based Learning is a teaching mode which is widely used in medical science teaching, biology management, especially in famous universities of Europe and America, such as Maastricht University, Stanford University. In China, the first PBL Education Alliance is established in February 2015. Different from traditional teaching method of teacher oriented education, PBL is teacher fronted and student oriented education. It is an educational mode which is student-centered, and it emphasizes active learning,

Problem-based learning method needs to determine a driving problem that is a practical problem to be solved. Students carry out research according to the problem, include looking up materials from resources sharing network platform and library, analyzing problem, confirming scheme. In this process, students and teachers must discuss each other, solve questions appeared in research procedure, summarize and rethink profoundly with the results at last. This kind of learning method claims a higher requirement for students, needs students to learn and apply the concept of scientific inquiry, establish the idea of autonomous learning, build a wide and flexible knowledge foundation, and cultivate students' ability of innovation and solving problems.

\section{TEACHING MODE RESEARCH}

Due to the contradiction between limitation of classroom time and course content, we explore the teaching mode based on resources sharing platform. In practice, following forms are adopted.

\section{A. PBL-Based Teaching}

In our practice, PBL-based teaching process includes four stages. At the beginning of the course, students of the class are divided into several teams, and teacher proposes problems and targets to achieve, and each team selects a problem. Every problem orients real signals which will be analyzed and processed, such as speech signal, electrocardio signal, etc. Then, along with deep learning of classroom knowledge, students begin to research how to solve the problem. At this stage, students look up references and other materials from Internet, resources sharing network platform, library, and so on. The third stage is exploring for solutions in groups outside classroom, in which students in one team cooperate with each other, and think by themselves. The fourth stage is presentation and discussion in class, each team makes a PPT of the results, answers and discusses questions proposed by teacher and other students. Fig. 2 is a photo of one team's presentation. Fig.3 is a GUI of Speech Signal processing system accomplished by a team. 


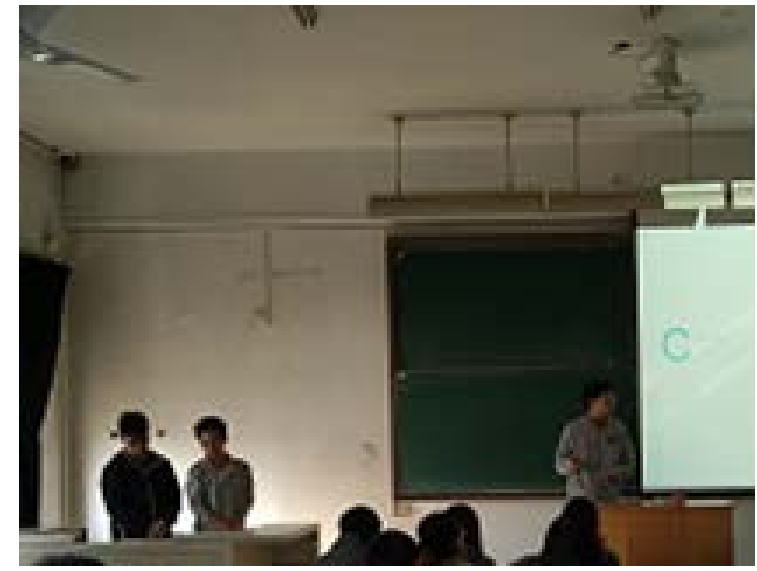

Fig. 2. Team Presentation

It obtains good results in this teaching method. The method urges students thinking, realizes the organism combination of theory and practice, promotes students' comprehension of the course content, improves students' ability of synthetic application of knowledge, analyzing problem independently, solving practical problems in engineering application, It also cultivates innovative thinking and scientific research spirit of student. At the end of the class, it is also very important to introspect for students. Through introspection, it will form the concept of the relationship between theory and practice, and students can draw lessons from the similar problems in the future.

\section{B. Main Point Based Teaching}

Key and difficult points can be taught emphatically in class, while basic and simple knowledge can be studied outside class using PPT or video from resources sharing platform. For example, Z-transform is already taught in Signal and Linear System course, so this concept can be mentioned briefly in Digital Signal Processing, and leaves more time to study other knowledge. And for students, mastering learning method is more important than learning specific knowledge. So we mainly explain learning methods of knowledge modules and application of tool software, which lays good foundation for autonomous learning.

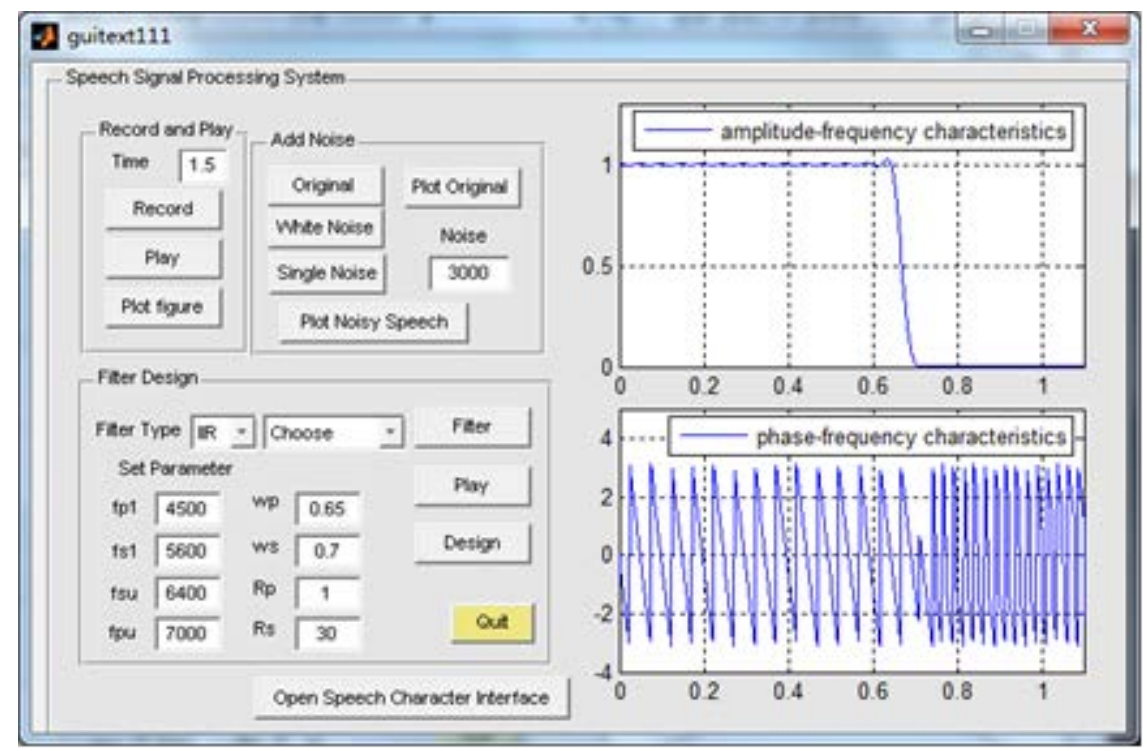

Fig. 3.GUI of Speech Signal processing system

\section{Case-Based Teaching}

Case-based method presents theory application, practical teaching, innovate training in case form, such as simple

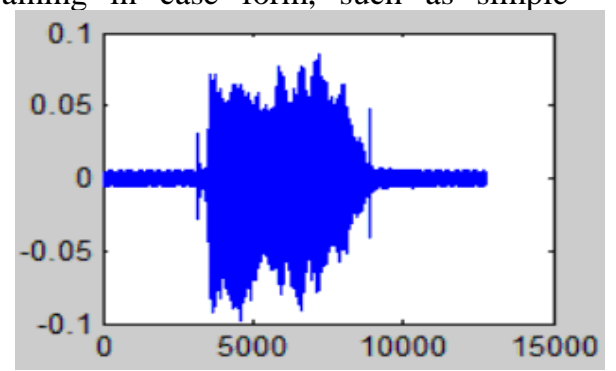

application of filter in engineering, Fig. 4 and Fig. 5 present an example of noisy speech enhancement using IIR filter.

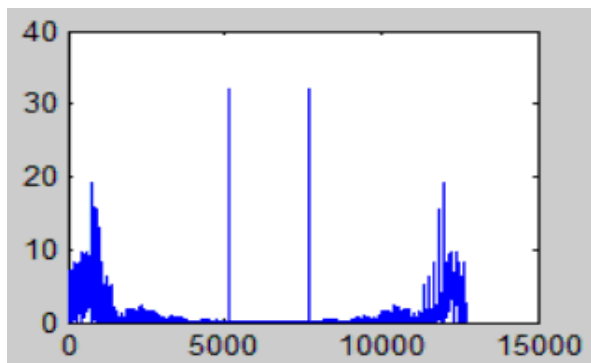

Fig. 4.Noisy speech and its frequency spectrum 

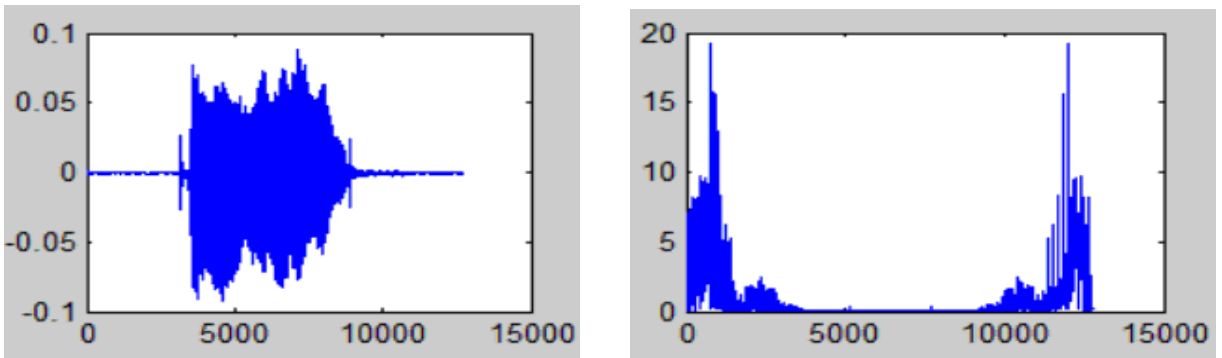

Fig. 5. Filtered speech and its frequency spectrum

In this method, examples are not selected casually and they must reflect teaching contents. Cases should have properties of closing to reality, attractiveness and moderate difficulty, attract students' interest, and make students think positively. For example, aim to explain Nyquist sampling theorem, we select the case of movie in which wheels of the car seems to wheel back while the car moves forward indeed. We find movie clip before class and cut it down. In classroom, we propose a question "It will cause what phenomenon in reality if sampling theorem is not meet?", then sampling theorem is obtained by formula derivation, and condition of restoring signal without distortion can be deduced. Next, movie clip is shown in screen, students analyze the reason of distortion and phenomenon caused by distortion. Finally, teacher summarizes form time domain and frequency domain in theory. All of these works make knowledge more closely to reality and practical engineering, easier to understand for students, and improve students' ability of analyze problems and solve problems.

\section{SUMMARY}

This paper discusses resources sharing network platform construction and teaching method reformation. Relying on objective and requirements of Electronic and Communication specialties, new teaching methods based on PBL and resources sharing network platform are explored. The reformation achieves good effects in teaching, and cultivates autonomous learning and innovative consciousness of students.

\section{ACKNOWLEDGEMENT}

This research was financially supported by the Education and Teaching Reform Research Project of Hebei University of Technology (Grant NO. 201502029) and the Higher Education and Teaching Reform Research and Practice Project of Hebei Province (Grant NO.2015GJJG267).

\section{REFERENCES}

[1] Higher Education Law of the People's Republic of China, information on http://old.moe.gov.cn/ publicfiles/business/htmlfiles/moe/moe_619/200407/1311. html.(In Chinese)

[2] National Outline for Medium-and Long-Term Educational Reform and Development (2010-2020), information on http://www.moe.edu.cn/publicfiles/business/htmlfiles/moe/moe_838/201 008/ 93704. html.(In Chinese)

[3] Y.P. Huang, Exploration on the construction of digital signal processing high-quality curriculum, Education and Vocation, no.32, pp.188189,2014. (In Chinese)

[4] Z.L.Luo, Teaching reform practice and exploration of digital signal processing course, Educational Review, no.2, pp, 124-126, 2015. (In Chinese)

[5] Z.M.Yang, X.Y.Peng, and Y.Yu, Research on practical teaching method for digital signal processing course, Research and Exploration in Laboratory, vol.33, no.9, pp.180-183, 2014. (In Chinese)

[6] L.D. Lin, The research and practice of digital signal processing training course, Research and Exploration in Laboratory, vol.33,no.6, pp. 219222, 2014. (In Chinese)

[7] S. Santos, G.Alexandre, A.Rodrigues, Applying PBL in project management education: A case study of an undergraduate course, IEEE Frontiers in Education Conference, pp.1-8, 2015.

[8] Y.P. Zhong, Y.J.Guo, X.Y.Luo, Application of Problem-Based Learning mode in nursing practice student teaching, 2015 7th International Conference on Information Technology in Medicine and Education (ITME), pp.385-389, 2015.

[9] T.Wiktorski, T.Hacker, R.A.Hansen, G.Rodgers, Experience with Problem-Based Learning in a hybrid classroom, 2015 IEEE 7th International Conference on Cloud Computing Technology and Science , pp.575-581, 2015.

[10] Z.M. Zhang, The construction of high-quality resource sharing Course under the background of the teaching reform in colleges and universities. The Guide of Science \& Education, no.3, pp.19-20, 2013.(In Chinese) 